\title{
PERENCANAAN LANSKAP BERBASIS MITIGASI BENCANA DI DESTINASI EKOWISATA PULAU SARONDE KABUPATEN GORONTALO UTARA
}

\author{
Rizkaf Zulfikar Kasim ${ }^{1 *}$, Ute Lies Siti Khadijah', Cecep Ucu Rakhman² \\ Rifki Rahmanda Putra ${ }^{1}$ \\ ${ }^{l}$ Magister Pariwisata Berkelanjutan, Sekolah Pascasarjana, Universitas Padjadjaran \\ ${ }^{2}$ Program Pascasarjana, Sekolah Tinggi Pariwisata Bandung \\ 1*Email:rizkaf19001@mail.unpad.ac.id
}

\begin{abstract}
ABSTRAK
Destinasi Ekowisata Pulau Saronde merupakan bagian dari Destinasi Pariwisata Nasional Togean - Gorontalo dan sekitarnya sebagai Destinasi Ekowisata Baru di Indonesia. Namun demikian kerentanannya terhadap bencana gempabumi yang mungkin saja berpotensi tsunami menjadikan destinasi ekowista tersebut perlu ditunjang ketahanan ekologisnya terhadap bencana-bencana yang mungkin dapat berdampak langsung pada Destinasi Ekowisata Pulau Saronde. Penelitian ini bertujuan untuk menganalisis potensi bencana dan merencanakan penataan lanskap dan vegetasi di Destinasi Ekowisata Pulau Saronde untuk mengurangi risiko apabila bencana terjadi di destinasi tersebut. Metode penelitian ini menggunakan pendekatan kualitatif dengan melalui beberapa proses tahapan perencanaan. Informan dalam penelitian ini berasal dari kalangan pemerintah yang membidangi kepariwisataan dan juga kebencanaan di Gorontalo Utara juga dari pihak pengelola Destinasi Ekowisata Pulau Saronde. Hasil penelitian menunjukkan Pulau Saronde memiliki kerentanan terhadap bencana gempabumi hingga tsunami karena berada pada jalur patahan dan memiliki beberapa catatan sejarah titik sumber gempa di bagian utara laut Sulawesi. Maka perencanaan lanskap melalui penataan ruang dan pemanfaatan vegetasi dapat diterapkan sebagai upaya menjembatani antara fungsi ekologis pulau dan fungsi pariwisata terutama bagi keamanan dan keselamatan wisatawan dan masyarakat setempat. Pihak pengelola beserta pemerintah setempat perlu melakukan tindakan struktural yang tegas mulai dari penentuan zonasi pulau, fasilitas pendukung seperti media interpretasi dan didukung regulasi non struktural seperti penetapan skenario mitigasi kebencanaan.
\end{abstract}

Kata Kunci: Destinasi Ekowisata Pulau Saronde; Perencanaan Lanskap; Mitigasi Bencana

\section{LANDSCAPE PLANNING BASED ON DISASTER MITIGATION AT SARONDE ISLAND ECOTOURISM DESTINATION NORTH GORONTALO DISTRICT}

\begin{abstract}
Saronde Island Ecotourism Destinations are part of the Togean National Tourism Destination - Gorontalo and its surroundings as a New Ecotourism Destination in Indonesia. However, its vulnerability to an earthquake that may have the potential for a tsunami makes this ecotourism destination need to be supported by its ecological resilience against disasters that may directly impact the Saronde Island Ecotourism Destination. This study aims to analyze the potential for disasters and plan the arrangement of the landscape and vegetation in the
\end{abstract}


Saronde Island Ecotourism Destination to reduce the risk if a disaster occurs in that destination. This research method uses a qualitative approach through several stages of planning processes. The informants in this study came from government circles in charge of tourism and disaster in North Gorontalo as well as from the management of the Saronde Island Ecotourism Destination. The results showed that Saronde Island is susceptible to earthquakes and tsunamis because it is on a fault line and has several historical records of earthquake source points in the northern part of the Sulawesi sea. So landscape planning through spatial planning and utilization of vegetation can be applied as an effort to bridge the ecological function of the island and the function of tourism, especially for the security and safety of tourists and local communities. Managers and local governments need to take firm structural measures, starting from determining island zoning, supporting facilities such as interpretation media, evacuation route and supporting non-structural regulations such as determining disaster mitigation scenarios.

\section{Keywords : Saronde Island Ecotourism Destination ; Landscape Planning ; Disaster Mitigation}

Copyright @2021. UHN IGB Sugriwa Denpasar. All Right Reserved

\section{PENDAHULUAN}

Pulau Saronde merupakan salah satu destinasi ekowisata berbasis pulau di Indonesia (tepatnya di Gorontalo Utara). Dalam dokumen kebijakan pada tingkat nasional ataupun daerah, Destinasi Wisata Pulau Saronde termasuk ke dalam Destinasi Pariwisata Nasional (DPN) Togean - Gorontalo dan sekitarnya sebagai Indonesia's Newest Ecotourism Destination (RIPPARNAS Tahun 2010-2025). Destinasi Wisata Pulau Saronde juga termasuk ke dalam Kawasan Destinasi Pariwisata Kabupaten Gorontalo Utara yang merupakan bagian dari Kawasan Strategis Pariwisata Provinsi (KSPP) Gorontalo dan bagian dari Kawasan Pengembangan pariwisata Nasional (KPPN) Kota Gorontalo-Limboto dan sekitarnya.

Di Destinasi Ekowisata Pulau Saronde terdapat ekosistem laut yang cukup lengkap mulai dari padang lamun hingga keanekaragaman terumbu karang, baik itu soft coral ataupun hard coral. Produk wisata yang disuguhkan pun yaitu wisata diving, snorkeling, wisata pantai dan aktifitas wisata bahari lainnya dengan pengembangan fasilitas pariwisata diarahkan pada pengembangan dive center, pusat informasi wisata, sarana wisata pantai, dan wisata bahari lainnya (RIPPARDA Provinsi Gorontalo Tahun 2019-2025).

Dibalik potensi ekowisatanya, Pulau Saronde berada pada wilayah dengan risiko bencana alam yang cukup tinggi. Berdasarkan Peta Geologi Gorontalo yang dirilis oleh Badan
Perencanaan, Penelitian dan Pengembangan Daerah (Bapppeda) Provinsi Gorontalo dan Badan Penanggulangan Bencana Daerah (BPBD) Gorontalo, menunjukkan bahwa adanya struktur sesar yang memotong wilayah Kabupaten Gorontalo Utara dengan jalur patahan Pantai Utara.

Hal tersebut menjadikan Destinasi Ekowisata Pulau Saronde yang merupakan destinasi tujuan wisata utama di Kabupaten Goronntalo Utara menjadi pulau atau daerah yang rawan bencana gempa bumi dan tsunami. Secara tektonik destinasi ini berada di wilayah pertemuan 2 lempeng besar, yakni Lempeng Pasifik dan Eurasia, serta lempeng-lempeng mikro. Maka rencana ke depan yang menjadi perhatian pemerintah yaitu, bahwa Kawasan Ekowisata Pulau Saronde termasuk ke dalam kawasan rawan bencana alam geologi (dalam hal ini tsunami) tersebut perlu akses publik seperti pemanfaatan sempadan pantai (lanskap) dalam menghadapi bencana pesisir (RTRW Kabupaten Gorontalo Utara Tahun 2011-2031).

Fokus pengembangan pariwisata Pemerintah Provinsi Gorontalo memang mengarah pada natural area yang memungkinkan wisatawan memiliki peluang untuk menikmati alam secara personal, namun berkelanjutan secara ekologis, dan memenuhi harapan konsumen (RIPPARDA Provinsi Gorontalo Tahun 2019-2025). Namun demikian, untuk meningkatkan kualitasnya, tata kelola destinasi dari segi mitigasi bencana tsunami khususnya, Pulau Saronde memerlukan 
evaluasi dan pembangunan infrastruktur yang mendukung mitigasi bencana untuk meminimalisir risiko terjadinya bencana tsunami. Khusus untuk destinasi yang memiliki sensitivitas dan kerentanan terhadap bencana, sistem mitigasi bukanlah pilihan, tetapi harus menjadi suatu kewajiban (Rahmafitria dan Misran, 2005).

Melalui pendekatan perencanaan lanskap berbasis mitigasi bencana tsunami, pengelola Destinasi Ekowisata Pulau Saronde tentunya dapat menerapkan skenario mitigasi struktural (Wulung \& Abdullah, 2020) misalnya dengan penataan vegetasi yang dapat memberikan efek ketika tsunami terjadi seperti trapping effect atau pemecah gelombang, escape effect atau sesuatu yang bisa dipanjat, dan soft landing sebagai penahan benturan ketika terbawa arus (Tanaka et al., 2007). Penataan lanskap yang tepat akan menjadi bagian dari suatu sistem mitigasi bencana.

Penataan lanskap berbasis mitigasi bencana juga merupakan salah satu alternatif yang baik, karena selain alami, baik terhadap ekosistem, memberikan kualitas visual yang baik bagi destinasi ekowisata (Meutia, 2013) dan juga efektif. Karena jenis tutupan vegetasi tersebut disesuaikan dengan ekosistem pulau dan juga akan berimplikasi pada kualitas lingkungan Destinasi Ekowisata Pulau Saronde

Namun demikian, dalam kurun waktu lima tahun terakhir, kajian mengenai mitigasi bencana di destinasi ekowisata masih minim dilakukan. Penelitian yang berkembang mengarah kepada pemahaman terkait ekowisata sebagai konsep pariwisata yang berpotensi berkembang setelah adanya Pandemi Covid-19 yang menuntut penerapan daya dukung lingkungan (Rudiyanto \& Sugiarto, 2020); ekowisata sebagai tools atau bentuk pengembangan pariwisata berbasis masyarakat (Asy'ari et al., 2021); dan pelestarian alam (Suryanti \& Indrayasa, 2021; Sudarti \& Hindiyati, 2021).

Padahal, di luar pada lokus destinasi ekowisata (dalam hal ini destinasi ekowisata Pulau Saronde), telah diterapkan beberapa skenario penataan lanskap untuk pemanfaatan dalam hal menjaga ekosistem pantai (Cristiano et al., 2020). Kemudian mitigasi pada kota di tengah pulau yang panas (Aleksandrowicz et al., 2017); ketahanan wilayah melalui sinergi antara pariwisata dan lanskap (Heslinga et al., 2020; Lafortezza et al., 2018); perencanaan lanskap kota berbasis mitigasi tsunami di Sumatera Barat (Ihsan, 2017); tata kelola lingkungan di pulau kecil St. Lucia (Mycoo et al., 2017); dan perencanaan lanskap berbasis mitigasi tsunami di Pangandaran dan Longsor di Bangli (Ayu et al., 2019; Ramdhany \& Makalew, 2016).

Ironisnya penelitian terkait dengan topik bencana di Destinasi Ekowisata Pulau Saronde masih jarang dilakukan. Satu-satunya penelitian terdahulu pada lokus dengan topik yang sama yaitu penelitian dari Djafar \& Sastrawati (2013) yang menjadi data awal terkait identifikasi daerah rawan bencana di Pulau Wisata Saronde. Penelitian tersebut juga menjadi salah satu rekomendasi bagi pentingnya penelitian terkait mitigasi bencana di Destinasi Ekowisata Pulau Saronde.

Adanya pemanfaatan lanskap di suatu pulau dengan secara hati-hati secara langsung juga akan menjaga keutuhan potensi sumber daya alam yang ada (Matheus et al., 2014); dapat menarik minat kunjungan orang untuk berwisata (Gold, 1980); dan mencegah terjadinya degradasi lingkungan (Gunn, 1994). Lebih dari itu, suatu mitigasi bencana akan memberikan gambaran bagi pengunjung atau wisatawan dalam meningkatkan persepsinya terhadap keamaman destinasi pariwisata (Laws \& Prideaux, 2005; Ritchie, 2009).

Berdasarkan dari latar belakang tersebut, maka penelitian ini bertujuan untuk menganalisis kondisi aktual Destinasi Ekowisata Pulau Saronde, menganalisis potensi kebencanaannya, dan menganalisis konsep rencana penataan lanskap (landscape plan) berbasis mitigasi bencana di Destinasi Ekowisata Pulau Saronde yang memiliki kerentanan terhadap bencana tsunami. Dari hasil analisis keseluruhan area pulau akan didapatkan hasil berupa rekomendasi penataan lanskap untuk Destinasi Wisata Pulau Saronde. Selain itu, penelitian ini juga diharapkan mampu menjadi contoh terkait tata kelola destinasi pariwisata berkelanjutan berbasis ketahanan terhadap bencana tsunami di destinasi wisata pesisir dan pulau-pulau kecil lainnya.

\section{TINJAUAN LITERATUR}

\section{Destinasi Ekowisata}

Ekowisata merupakan suatu pemikiran yang mempunyai tujuan untuk melestarikan sumberdaya serta memanfaatkannya untuk kepentingan wisata secara bertanggung jawab. 
Dalam hal ini konsep pemanfaatannya harus disesuaikan dengan sumberdaya yang ada dan daya dukungnya terhadap kegiatan wisata (Hutabarat et al., 2009). Pertama kali ekowisata diperkenalkan oleh TIES (The International Ecotourism Society) tahun 1990 yaitu sebagai bentuk perjalanan ke natural area dengan tujuan mengkonservasi lingkungan dan mensejahterakan penduduk setempat (Linberg dan Hawkins, 1993).

Dalam pelaksanaannya ekowisata di pesisir, laut, dan pulau-pulau kecil tidak boleh mengeksploitasi alam, tetapi hanya menggunaka jasa pemanfaatan alam dan masyarakat untuk memenuhi kebutuhan fisik, psikologis, dan pengetahuan baru (Tuwo, 2011). Dapat dikatakan ekowisata bukan hanya menjual destinasi wisata namun jauh dari itu, ekowisata menjual filosofi dari suatu tempat melalui kegiatan pendidikan dan interpretasi terhadap lingkungan alam dan budaya masyarakat dengan pengelolaan kelestarian ekosistem pesisir dan laut.

\section{Perencanaan Pariwisata}

Perencanaan pariwisata merupakan suatu proses sistematis untuk mempersiapkan kegiatan yang akan dilakukan untuk mencapai suatu tujuan tertentu yang pada hakekatnya terdapat pada setiap jenis usaha pariwisata (Wadiyanto \& Baiquni, 2011). Hal tersebut diperkuat oleh pendapat Knudson (1980), bahwa perencanaan pariwisata merupakan kegiatan pengumpulan dan menginterpretasikan data, memproyeksikannya ke masa depan, mengidentifikasi masalah dan memberi pendekatan yang beralasan untuk memecahkan masalah-masalah tersebut.

Perencanaan merupakan proses kompleks yang mempertimbangkan berbagai aspek (pendekatan) untuk mencapai suatu tujuan dan memecahkan masalah-masalah yang ada. Adapun aspek dalam perencanaan yang perlu dipertimbangkan adalah aspek sarana prasarana fisik, hukum, promosi, keuangan, pasar ekonomi, manajemen, sosial budaya masyarakat, dan aspek lingkungan (Wardiyanto, 2011). Adapun 6 proses mendasar dalam perencanaan menurut Gunn \& Var (2002) adalah sebagai berikut beserta penjelasannya: (1) Persiapan awal, yaitu studi awal dengan menentukan jangka waktu hingga struktur organisasi; (2) Tujuan dan sasaran, yaitu mementukan sasaran apa saja yang akan dicapai;
(3) Survei, yaitu proses inventarisasi segala informasi terkait kondisi eksisting dan karakteristik dari kawasan yang akan diteliti; (4) Analisis dan sintesis, yaitu perumusan kebijakan pembangunan dan rencana; dan (5) Rekomendasi, yaitu perumusan rekomendasi berdasarkan aspek yang telah ditentukan.

\section{Penataan Lanskap Berbasis Mitigasi Tsunami}

Kegiatan mitigasi bencana dilakukan melalui pelaksanaan penataan ruang (pengaturan pembangunan, pembangunan infrastruktur, dan tata bangunan) dan melalui penyelenggaraan pendidikan, penyuluhan, dan pelatihan baik secara konvensional maupun modern (Wulung \& Abdullah, 2020). Dalam konteks mitigasi bencana melalui perencanaan lanskap, menurut Faulkner, (2001; 2002) hal tersebut termasuk ke dalam kegiatan sebelum bencana terjadi dan masuk kepada tatanan struktural atau melalui pelaksanaan penataan ruang alami.

Proses perencanaan pada penelitian ini lebih kepada pendekatan sumber daya. Di mana sumber daya yang dimaksud adalah sumber daya lanskap di Destinasi Wisata Pulau Saronde baik dari segi aspek biotik seperti vegetasi dan juga aspek abiotik seperti geomorfologi dan kebencanaan di Destinasi Wisata Pulau Saronde.

Subroto (dalam Ayu et al., 2019), menambahkan bawah dalam proses perencanaan lanskap terdapat 6 tahapan yang dapat dilakukan yaitu: (1) Identifikasi potensi ruang; (2) Identifikasi faktor penghambat pengembangan ruang; (3) Identifikasi kebutuhan dan kepentingan pengembangan; (4) Identifikasi spesifikasi kegiatan pembangunan dan dampaknya terhadap komponen lanskap; (5) Identifikasi koneksitas antar kegiatan dengan daya dukung ruang; (6) Identifikasi dan analisis kebijakan dan peraturan yang relevan mendukung pemanfaatan ruang yang berkelanjutan. Dalam hal ini penataan lanskap berarti mengatur tata ruang menjadi beberapa bagian (sesuai fungsi dan daya dukungnya), perencanaan tutupan lahan vegetasi sebagai buffer zone, dan untuk meningkatkan kualitas visual juga menjaga kualitas lingkungan destinasi ekowisata.

\section{METODE}

Objek dalam penelitian ini adalah Destinasi Ekowisata Pulau Saronde yang terletak di 
wilayah Desa Ponelo, Kecamatan Kwandang, Kabupaten Gorontalo Utara (BPS Kab Gorontalo Utara, 2019). Paradigma penelitian ini merupakan post-positivisme atau berpikir ilmiah secara induksi atau menarik kesimpulan dari satu atau lebih fakta lapangan (Poulus \& Tahir, 2018: 58 ), berfikir dari khusus ke umum didasari oleh pengalaman penelitian saat melakukan observasi lapangan.

Metode penelitian yang digunakan adalah penelitian kualitatif. Berdasarkan pandangan Denzin (2012); Wisdom \& Creswell (2013); dan Sekaran \& Bougie (2016) metode penelitian dengan pendekatan kualitatif merupakan bidang multi-disiplin, memiliki sifat berusaha mengungkapkan gejala secara komprehensif melalui pengumpulan data yang sifatnya alami atau berdasarkan fakta lapangan setelah observasi dan juga wawancara terhadap sumber data.

Data primer dalam penelitian ini didapatkan dari hasil observasi dan wawancara kepada informan penelitian yang dipilih melalui purposive sampling seperti Dinas Pariwisata Gorontalo Utara, BPBD Gorontalo Utara dan PT Gorontalo Alam Bahari sebagai badan pengelola Pulau Saronde. Sedangkan data sekunder melalui studi literatur dari artikel jurnal, media elektronik, dan dokumen kebijakan dari instansi terkait.

Data dianalisis menggunakan teknik analisis data interaktif dengan tahapan (Wisdom \& Creswell, 2013): (1) Pengumpulan data; (2) Reduksi data; (3) Display data; dan (4) Verifikasi data. Tahapan analisis tapak juga digunakan pada penelitian ini untuk menghasilkan sintesis berupa konsep penataan langskap. Tahapan tersebut mengacu pada proses perencanaan dari Gold (1980): Inventarisai kondisi eksisting terkait biofisik, tata guna lahan, kebencanaan; analisis potensi dan kendapa tapak; dan sintesis konsep pentaan lanskap.

\section{HASIL DAN PEMBAHASAN}

\section{Gambaran Umum dan Potensi Destinasi Ekowisata Pulau Saronde}

Destinasi Ekowisata Pulau Saronde terletak pada $00^{\circ} 55^{\prime} 32,10^{\prime \prime} \mathrm{LU}-122^{\circ} 51^{\prime} 54,30^{\prime \prime} \mathrm{BT}$ dengan batas-batas wilayah administratif pada sisi utara berbatasan dengan Laut Sulawesi, sisi barat berbatasan dengan Pulau Bugisa, sisi timur berbatasan dengan Pulau Mohinggito, dan sisi selatan berbatasan dengan Desa Moluo. Luasan pulau ini kurang lebih sekitar $10 \mathrm{Ha}$. Gorontalo Utara sendiri memiliki curah hujan $1625 \mathrm{~mm}$ dengan 178 hari hujan dalam satu tahun dan suhu rata-rata sekitar $26,80^{\circ} \mathrm{C}$ (BPS Kab Gorontalo Utara, 2019).

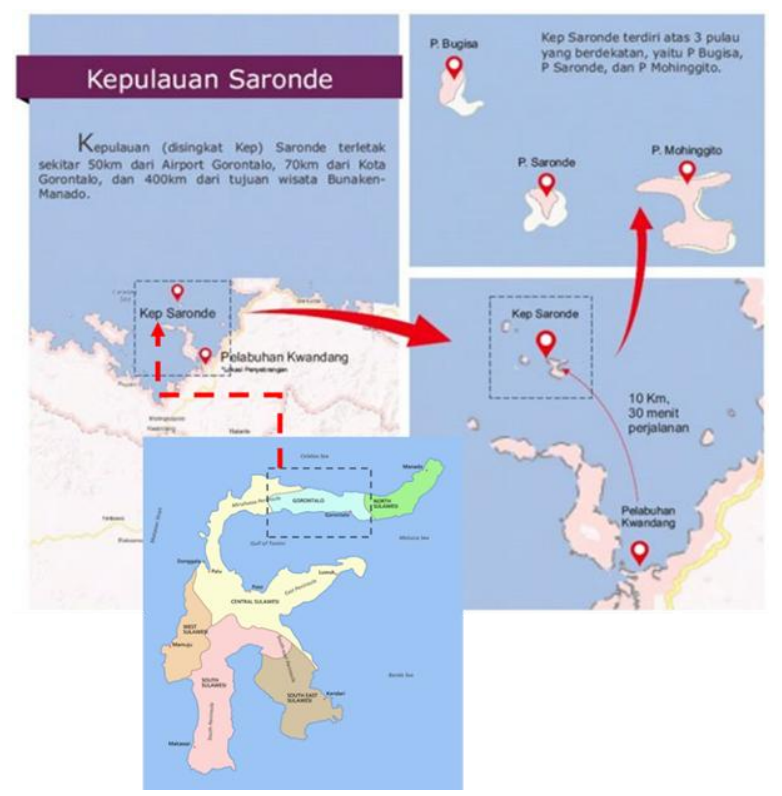

Gambar 1. Peta Lokasi Pulau Saronde Sumber: Modifikasi dari sarondeislands.com

Ekosistem Destinasi Ekowisata Pulau Saronde terdiri atas laut, perairan pantai, pesisir dan area bangunan fasilitas wisata. Pulau ini berada di bawah kepengelolaan PT Gorontalo Alam Bahari dan Dinas Pariwisata Gorontalo Utara. Pulau ini bukan merupakan pulau yang berpenghuni, namun demikian masyarakat di sekitar kecamatan atau desa banyak yang menggantungkan perekonomian dari adanya kegiatan pariwisata di pulau tersebut. Ada yang bertugas menjaga pulau tersebut, ada yang menjadi jasa perahu angkut wisatawan, ada pula yang memasok bahan baku seperti ikan untuk menjadi bahan olahan wisatawan.

Aksesibilitas menuju Pulau Saronde ini dapat ditempuh menggunakan transportasi darat dan laut. Dari pusat kota Provinsi Gorontalo, wisatawan dapat menggunakan transportasi darat menuju ke Pelabuhan Kwandang dengan jarak tempuh sekitar $65 \mathrm{~km}$ dan kemudian dilanjutkan dengan perahu penyebrangan.

Sebagai destinasi ekowisata, Pulau Saronde menyuguhkan berbagai potensi alam berupa ekosistem bawah laut yang masih alami seperti tutupan fauna seperti spesies ikan-ikan terumbu 
karang mulai dari ikan kakatua, ikan bendera, baronang, kakap, giru, ikan kuli pasir, ikan kepekepe. Kemudian terdapat juga tutupan keanekaragaman fauna terumbu karang yang dapat dinikmati melalui aktivitas wisata snorkeling (Gambar 2).
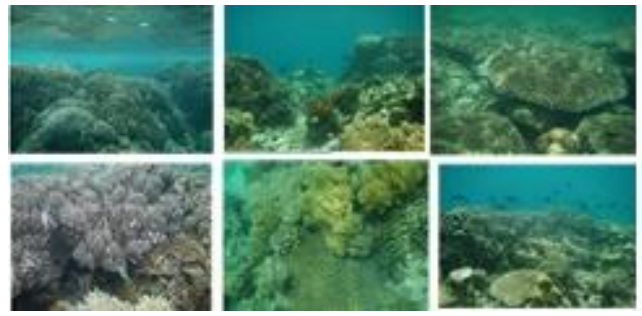

Gambar 2. Keanekaragaman Terumbu Karang Pulau Saronde

Sumber: Pengelola Pulau Saronde (2020)

Keindahan alam Pulau Saronde juga dapat terlihat dari hamparan pasir putih, batu granit dan vegetasi alami di sekitar pulau. Sedangkan jenis fasilitas yang tersedia antara lain seperti shelter, dermaga kapal penumpang, cottage, gazebo, ketersedian listrik melalui genset, aula pertemuan, juga ketersediaan air bersih. Bagi wisatawan yang menginginkan aktivitas snorkeling, pengelola juga telah menyediakan peralatan berupa masker dan snorkle.

\section{Potensi Bencana di Destinasi Ekowisata Pulau Saronde}

Dari hasil observasi lapangan pada 13 Desember 2020, hasil studi dari berbagai literatur, dan wawancara terhadap Dinas Pariwisata dan Bappeda Gorontalo, setidaknya ditemui fakta terkait Destinasi Ekowisata Pulau Saronde berada pada kawasan bencana gempabumi tinggi dan berada pada jalur patahan pantai utara (Gambar 3). Kawasan yang berada di sekitar Pulau Saronde juga berpotensi terjadi retakan tanah, pelulukan, gerakan tanah atau pergeseran tanah.

Adapun potensi bencana lainnya menurut penelitian awalan yang dilakukan Djafar (2013) yaitu adalah : (1) Abrasi yang meliputi daerah bagian utara pulau dengan tingkat kerawanan tinggi; (2) Kenaikan paras muka air laut yang meliputi seluruh daerah pulau dengan tingkat kerawanan sedang; dan (3) Tsunami meliputi nyaris seluruh kawasan pulau yang dilihat berdasarkan ketinggian kawasan. Dalam fokus penelitian ini, fokus bencana yang diasumsikan adalah kerawanan terhadap ancaman bencana tsunami akibat dari resiko terjadinya gempa bumi dan gerakan patahan pantai utara Gorontalo.

Di mana, riwayat gempa yang terjadi di bagian utara laut Sulawesi (Gambar 3) mulai dari tahun 1990 memiliki kekuatan sekitar 7 SR, pada tahun selanjutnya memiliki kekuatan 7,2 SR dan pada tahun 2008 terjadi kembali gempa dengan kekuatan 7,7 SR. Ditinjau dari rata-rata kekuatannya, gempa dengan kekuatan tersebut tentu berpotensi menimbulkan tsunami. Maka perlu ada upaya skenario-skenario mitigasi bencana dan manajemen krisis untuk mengantisipasi hal tersebut.

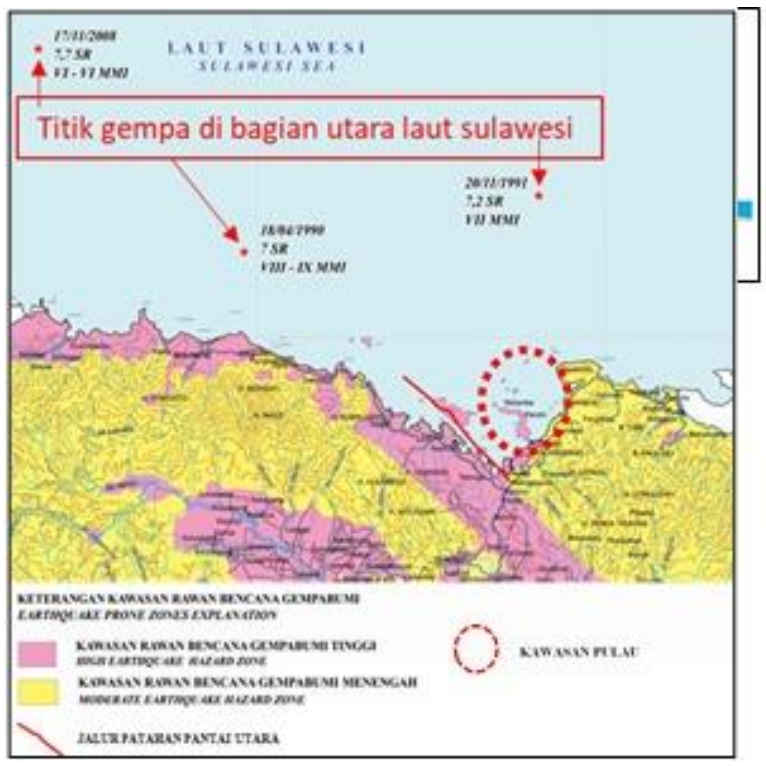

Gambar 3. Peta Kawasan Rawan Bencana Gempabumi dan Patahan Gorontalo

Sumber: Modifikasi dari PVMBG (2011); Bappeda Provinsi Gorontalo

\section{Konsep Penataan Lanskap Berbasis Mitigasi Tsunami melalui Pemanfaatan Ruang dan Vegetasi}

Ekowisata berarti jembatan antara fungsi konservasi dan budidaya (pariwisata). Sambil menghasilkan peluang ekonomi dari pemanfaatan jasa lingkungan, kegiatan ekowisata berprinsip pada pelestarian lingkungan tanpa mengubah keutuhan ekosistem. Sehingga masyarakat mendapatkan manfaat dari kegiatan pariwisata dan juga manfaat dari konservasi sumber daya alam (McCormick, 1994). Penelitian ini mengadaptasi apa yang dikemukakan Keliwar et al., (2015), bahwa ekowisata merupakan bentuk pariwisata yang mengenali dampak-dampak penting terhadap lingkungan, sosial-budaya dan 
ekonomi baik yang disebabkan oleh kegiatan pariwisata.

Dalam hal ini, perencanaan lanskap dimaksudkan untuk optimalisasi pemanfaatan lingkungan untuk memitigasi atau meminimalisir risiko apabila terjadi bencana yang telah diidentifikasi pada Sub-bab sebelumnya. Berikut di bawah ini Tabel 1 yang menunjukkan hasil identifikasi potensi ruang, penghambat pengembangan, dan lain sebagainya dari proses observasi lapangan, studi literatur, dan wawancara terhadap BPBD dan PT Gorontalo Alam Bahari untuk penentuan analisis lanskap (pada komponen ruang dan vegetasi) untuk mitigasi bencana tsunami.

Tabel 1. Potensi dan Penghambat Perencanaan Lanskap

\section{Kondisi Eksisting \\ Deskripsi}

\begin{tabular}{ll}
\hline Kondisi ruang & Timur laut - utara: batuan \\
& granit, Timur - barat laut: \\
& hamparan pasir putih, utara: \\
& anekaragam vegetasi \& \\
& pephononan di atas bukit berbatu, \\
& Selatan: kontur tanah datar \& \\
& vegetasi cemara pantai, tengah: \\
& bukit (Gambar 4)
\end{tabular}

Faktor-faktor penghambat

Belum adanya Tempat Evakuasi Sementara (TES), jalur evakuasi, rambu assembly point dan skema mitigasi bencana

Kebutuhan \& kepentingan

Titik TES, Jalur evakuasi, ramburambu, Early Warning System (EWS), dsb

Sumber: Data Primer (2020)

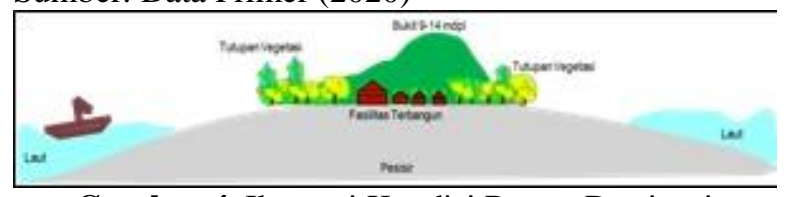

Gambar 4. Ilustrasi Kondisi Ruang Destinasi Ekowisata Pulau Saronde

Sumber: Data Primer (2020)

Kondisi eksisting mengenai upaya mitigasi yang telah dilakukan di Destinasi Ekowisata Pulau Saronde berdasarkan hasil observasi dan wawancara dengan PT Gorontalo Alam Bahari, menunjukkan bahwa pengelola fokus terhadap tata bangunan fasilitas pariwisata yang dibangun tidak boleh pada zona penyangga atau zona pesisir. Bentuk bangunan fasilitas wisata seperti akomodasi dan lainnya juga dibuat semi permanen untuk mempertimbangkan daya dukung lingkungan.

Adapun kegiatan pengembangan atau penataan lanskap yang berdampak terhadap komponen lanskap setelah mempertimbangkan kondisi eksisting pada Tabel 1 di atas yaitu adalah:

(1) Pembagian zonasi (Gambar 5)

a. Zona wisata pantai

Zona ini ditunjukkan dengan warna krem. Zona ini merupakan area potensi wisata bahari di Destinasi Ekowisata Pulau Saronde, dengan kelas penggunaan yang dapat dikembangkan namun perlu dilestarikan, menghindari konflik pemanfaatan yang tidak sesuai, meningkatkan daya dukung, konservasi, pemanfaatan lahan secara efisien untuk memastikan pengembangan terencana untuk jangka panjang. Zona ini harus ditekan untuk aktivitas wisata smaller size bukan mass tourism untuk menjaga fungsi ekologisnya. Zona ini berada di 100 meter dari garis pantai

b. Zona penyangga (Gambar 6)

Zona ini ditunjukkan dengan warna hijau. Zona ini merupakan zona extensive use (minim pembangunan), dapat mempengaruhi persepsi awal pengunjung tentang daya tarik wisata karena sifat areanya harus bersifat alami, tidak terdapat bentuk pengembangan apapun yang bersifat komersial, dan pemandangan yang baik tetap harus dipelihara. Dalam hal ini zona penyangga menjadi bentuk pemanfaatan vegetasi untuk mitigasi tsunami. Kondisi eksisting di Destinasi Ekowisata Pulau Saronde, tutupan vegetasinya antara lain Beringin, Cemara Pantai, Kelapa yang dapat dimanfaatkan sebagai escape effect atau sesuatu yang dapat dipanjat dan Padang Lamun (Cymodocea rotundata) yang dapat dimanfaatkan sebagai soft landing atau bantalan atau peredam dari benturan keras. Arah program pelestarian Mangrove juga perlu diinisiasi sebagai greenbelt tsunami (Vermaat \& Thampanya, 2006) sebagai trapping effect atau pemecah gelombang. 
c. Zona evakuasi sementara

Zona ini ditunjukkan dengan warna kuning. Penentuan sirkulasi untuk jalur evakuasi sementara didasarkan pada lanskap topografi bukit pada pulau tersebut dengan ketinggian 9-14 mdpl. Di zona ini diperuntukkan bagi titik kumpul wisatawan untuk evakuasi sementara karena berada pada zona kerentanan bencana rendah. Pada zona ini, perlu disediakan supply makanan dan obat-obatan yang cukup, persediaan alat Pertolongan Pertama Pada Kecelakaan (P3K), air bersih, atau mungkin vegetasi yang jenis-jenisnya dapat dimanfaatkan untuk sumber pangan wisatawan selama belum dievakuasi ke luar pulau. Namun demikian vegetasi yang dimanfaatkan, harus sesuai dengan ekosistem di Destinasi Ekowisata Pulau Saronde.

(2) Aksesibilitas

a. Jalur sirkulasi wisatawan

Jalur ini diperuntukkan sebagai aksesibilitas bagi wisatawan selama beraktivitas wisata di Destinasi Ekowisata Pulau Saronde. Jalurnya ditunjukkan dengan garis merah putusputus dan simbol garis coklat.

b. Jalur evakuasi

Jalur ini dikhususkan untuk akses darurat apabila terjadi indikasi terjadinya gempabumi atau tsunami. Jalur ini sebagai aksesibilitas menuju zona evakuasi sementara. Pada jalur ini, penataan lanskap diarahkan dengan tutupan vegetasi penunjuk arah dan dengan penunjuk jalur evakuasi buatan.

(3) Media Interpretasi (Moscardo, 1998; Orams, 1996)

a. Personal

Interpretasi personal atau interpretasi langsung, medianya adalah melalui seorang interpreter. Guide belum tentu interpreter, namun demikian interpreter dapat dkatakan sebagai guide. Hal tersebut dikarenakan interpretasi merupakan seni menceritakan sesuatu objek atau subjek di destinasi wisata dengan berbagai teknik (guided tour, teatrikal, experiential learning, dsb) dengan tujuan membangun awareness wisatawan terhadap nilai-nilai pada destinasi tersebut dan juga mendorong perubahan sikap wisatawan pasca kunjungan ke arah yang lebih baik sesuai makna pesan. Pesan yang dapat disampaikan interpreter di Destinasi Ekowisata Pulau Saronde yaitu dapat terkait dengan menjaga kelestarian lingkugan ekosistem mangrove, terumbu karang, dsb. Kemudian tidak lupa untuk menyampaikan edukasi terkait kesiapsiagaan bencana pesisir dan pulau kecil. Namun demikan, perlu adanya pelatihan interpretasi berbasis partisipasi bagi masyarakat (Siri \& Chantraprayoon, 2017) di sekitar Kecamatan Kwandang yang menjadikan sektor pariwisata di Destinasi Ekowisata Pulau Saronde sebagai sumber mata pencaharian.

b. Non Personal

Interpretasi non personal atau interpretasi tidak langsung, medianya adalah melalui papan interpretasi, video interaktif, alat peragaan, dan lain sebagainya. Materu pada media interpretasi non personal untuk Destinasi Ekowisata Pulau Saronde dapat berupa komunikasi persuasif untuk menjaga lingkungan setempat dan juga tentang rambu-rambu bahaya.

(4) Skenario mitigasi kebencanaan (Kemenpar, 2018)

a. Pemahaman mitigasi

Mengurangi atau menghilangkan potensi bencana (krisis) dengan mendesain lanskap tata ruang, vegetasi, dan membuat regulasi terkait yang kondusif atau mendukung mitigasi bencana di Destinasi Ekowisata Pulau Saronde. Berdasarkan hasil temuan penelitian, regulasi terkait mitigasi bencana sudah diatur pada BPBD Gorontalo Utara. Namun pihak pengelola PT Gorontalo Alam Bahari belum melakukan implementasi pada tahap pemahaman mitigasi ini.

b. Kesiapsiagaan destinasi

Dalam tahapan ini, Destinasi Ekowisata Pulau Saronde sudah memiliki ekosistem kebencanaan yang diterbitkan oleh Bappeda Provinsi Gorontalo terkait kawasan rawan gempabumi dan jalur patahan. Namun demikian yang perlu ditegaskan pada tahapan ini yaitu harus adanya simulasi dan pelatihan tanggap bencana di sekitar destinasi ekowisata, EWS atau pernyataan darurat dan tindakan perlindungan. 
c. Keandalan tanggap darurat

Tahapan ini merupakan rencana tanggap darurat ketika bencana terjadi. Fokus dalam tahapan ini adalah perlindungan bagi unsur kepariwisataan yang terdampak apabila bencana terjadi. Pada tahap ini kualitas informasi melalui crisis center diperlukan manajemen pengelolaan media yang baik.

d. Pemulihan destinasi

Tahapan ini adalah langkah memperbaiki, memulihkan dan membangun ulang citra destinasi, fisik destinasi, dan lain sebagainya apabila bencana terjadi. Dengan perlahan aktivitas wisata berjalan kembali.

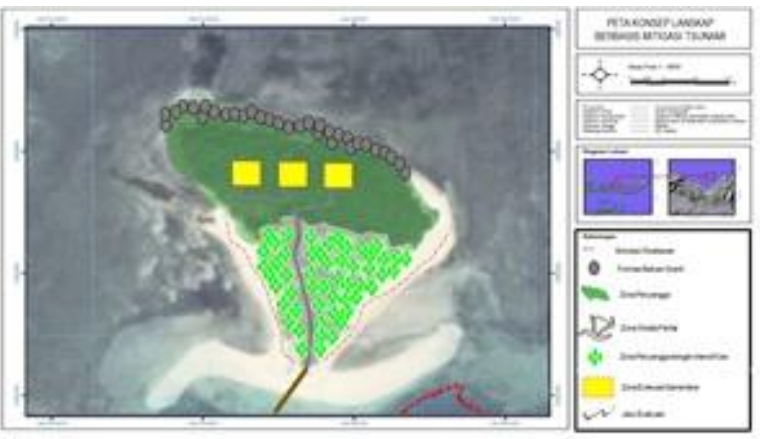

Gambar 5. Konsep Zonasi Lanskap Pulau Saronde Berbasis Mitigasi Tsunami Sumber: Data Primer (2020)

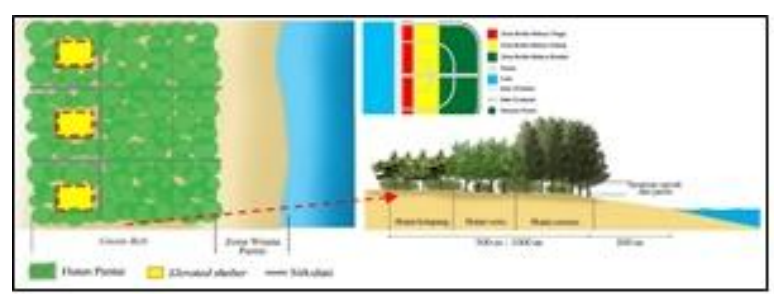

Gambar 6. Konsep Penataan Lanskap Vegetasi Pada Zona Penyangga

Sumber: Modifikasi dari Ihsan (2017)

Penelitian ini mengarah kepada konsep ketahanan lingkungan Destinasi Ekowisata Pulau Saronde, terhadap bencana alam (khususnya tsunami) melalui tata kelola destinasi. Perlu digarisbawahi, bahwa perencanaan lanskap berbasis mitigasi bencana melalui penataan ruang dan pemanfaatan vegetasi merupakan langkah meminimalisir risiko terhadap ancaman bencana gempa bumi dan tsunami di Destinasi Ekowisata Pulau Saronde melalui pendekatan pembangunan infrastruktur dengan penataan fasilitas pendukung mitigasi bencana (TES, EWS, jalur evakuasi, media interpretasi) dan didukung oleh regulasi mengenai skenario mitigasi kebencanaan. Pendekatan perencanaan lanskap dengan penataan ruang dan pemanfaatan vegetasi di Destinasi Ekowisata Pulau Saronde menjadikan destinasi tersebut secara ekologis dan visual tetap terjaga keaslian dan kealamiannya namun demikian tidak mengurangi ketahanan destinasi ekowisata tersebut terhadap ancaman bencana gempabumi dan tsunami.

\section{SIMPULAN}

Pengembangan ekowisata di Destinasi Wisata Pula Saronde didasarkan pada keanekaragaman hayati pulau tersebut yang perlu dijaga fungsi ekologisnya. Seperti tutupan terumbu karang dan biota laut di dalamnya, ekosistem mangrove dan lain sebagainya. Secara eksisting destinasi ekowisata tersebut berada dekat dengan jalur patahan Pantai Utara Gorontalo dan berada pada kawasan rawan bencana gempabumi dengan catatan sejarah gempa yang terjadi pada 1990, 1991 dan 2008 di bagian utara laut Sulawesi dengan rata-rata kekuatannya mencapai 7 SR. Hal tersebut menjadikan penataan ruang dan pemanfaatan vegetasi di Destinasi Ekowisata Pulau Saronde dapat diarahkan untuk tetap menjaga fungsi ekologis ekosistemnya, namun demikian dapat tahan terhadap bencana. Maka upaya perencanaan lanskap yang dapat diterapkan di pulau tersebut yaitu perlu adanya pembagian zonasi, jalur evakuasi, media interpretasi dan didukung skenario mitigasi kebencanaannya.

\section{REFERENSI}

Aleksandrowicz, O., Vuckovic, M., Kiesel, K., \& Mahdavi, A. (2017). Current trends in urban heat island mitigation research: Observations based on a comprehensive research repository. In Urban Climate. https://doi.org/10.1016/j.uclim.2017.04.002

Ayu, D., Utami, N. A., \& Asna, I. M. (2019). Perencanaan Lanskap Permukiman Berbasis Mitigasi Bencana Longsor Di Kecamatan Kintamani Kabupaten Bangli. Jurnal Ilmiah Telsinas.

Cristiano, S. da C., Rockett, G. C., Portz, L. C., \& Souza Filho, J. R. de. (2020). Beach landscape management as a sustainable tourism resource in Fernando de Noronha Island (Brazil). Marine Pollution Bulletin, 150(June 2019), 110621. https://doi.org/10.1016/j.marpolbul.2019.11 
0621

Denzin, N. K. (2012). Triangulation 2.0 Contesting Mixed Methods Experimentalism. Journal of Mixed Methods Research.

Djafar, N. W. R. E. M. I \& Sastrawati, S. (2013). Identifikasi Daerah Rawan Bencana di Pulau Wisata Saronde Kabupaten Gorontalo Utara. Prosiding Temu Ilmiah IPB, 41-47.

Faulkner, B. (2001). Towards a framework for tourism disaster management. Tourism Management.

https://doi.org/10.1016/S0261-

5177(00)00048-0

Faulkner, Bill. (2002). Towards a framework for tourism disaster management. In Managing Tourist Health and Safety in the New Millennium.

https://doi.org/10.4324/9780080510798

Gold, Seymour. M. (1980). Recreation Planning and Design. United States of Amerika: McGraw-Hill, Inc.

Gunn, C. A., \& Var, T. (2002). Tourism planning: Basics, concepts, cases. Psychology Press.

Heslinga, J., Groote, P., \& Vanclay, F. (2020). Towards resilient regions: Policy recommendations for stimulating synergy between tourism and landscape. Land. https://doi.org/10.3390/land9020044

Hutabarat, A. A., Yulianda, F.,Fahrudin, A., Harteti, S., Kusharjani.2009. Pengelolaan Pesisir dan Laut Secara Terpadu. Pusdiklat Kehutanan-Departemen Kehutanan RISECEM-Korea International Cooperation Agency.Bogor.

Ihsan, F. (2017). Perencanaan Lanskap Kota Pariaman Provinsi Sumatera Barat Berbasis Mitigasi Tsunami. Jurnal Lanskap Indonesia.

https://doi.org/10.29244/jli2017911-12

Keliwar, S., Kajian, M., Sekolah, P., Universitas, P., \& Mada, G. (2015). Pola Pengelolaan Ekowisata Berbasis Komunitas Di Taman Nasional Gunung Halimun Salak. Jurnal Nasional Pariwisata, 5(2), 110-125. https://doi.org/10.22146/jnp.6371

Kemenpar RI. (2018). Pengelolaan Krisis Kepariwisataan: Prosedur Operasional Standar Aktivasi Tourism Crisis Center. Jakarta: Kementerian Pariwisata Republik Indonesia

Asy'ari, R., Dienaputra, R. D., Nugraha, A., Tahir, R., Rakhman, C. U \& Putra, R. R. (2021). Kajian Konsep Ekowisata Berbasis
Masyarakat Dalam Menunjang Pengembangan Pariwisata : Sebuah Studi Literatur. Pariwisata Budaya: Jurnal Ilmiah Pariwisata Agama dan Budaya, 6(1), 10-19.

Knudson, D.M. (1980). Outdoor recreation. London: Mac Millan Publishing Co., Inc.

Lafortezza, R., Chen, J., van den Bosch, C. K., \& Randrup, T. B. (2018). Nature-based solutions for resilient landscapes and cities. Environmental Research. https://doi.org/10.1016/j.envres.2017.11.03 8

Laws, E., \& Prideaux, B. (2005). Special Issue: Tourism crises: management responses and theoretical insight. Journal of Travel \& Tourism Marketing.

Lindberg, K. dan Hawkins, D.E. 1993. Ekoturism: Petunjuk untuk Perencana dan Pengelola. The Ecotourism Society. North Bennington, Vermont.

Meutia, Z. D. (2013). Desain Lansekap Sebagai Mitigasi Bencana Tsunami. Unimal Press.

Moscardo, G. (1998). Interpretation and sustainable tourism: functions, examples and principles. Journal of Tourism Studies.

Mycoo, M. A., Griffith-Charles, C., \& Lalloo, S. (2017). Land management and environmental change in small-islanddeveloping states: the case of St. Lucia. Regional Environmental Change. https://doi.org/10.1007/s10113-016-1050-z

Orams, M. B. (1996). Using interpretation to manage nature-based tourism. Journal of Sustainable Tourism. https://doi.org/10.1080/0966958960866726 0

Peraturan Daerah Kabupaten Gorontalo Utara Nomor 5 Tahun 2013 Tentang Rencana Tata Ruang Wilayah Kabupaten Gorontalo Utara Tahun 2011-2031

Peraturan Daerah Provinsi Gorontalo Nomor 2 Tahun 2019 Tentang Rencana Induk Pembangunan Pariwisata Daerah Tahun 2019-2025

Peraturan Pemerintah Republik Indonesia Nomor 50 Tahun 2011 Tentang Rencana Induk Pembangunan Kepariwisataan Nasional Tahun 2010-2025

Poulus, S \& Rusdin. (2018). Metodologi Penelitian Sosial Suatu Pendekatan Teori dan Praktis. Alfabeta

Ramdhany, R. R., \& Makalew, A. D. N. (2016). Perencanaan Lanskap Pantai Pangandaran Berbasis Mitigasi Bencana Tsunami Coastal Landscape Planning in Pangandaran. E- 
Jurnal Arsitektur Lansekap.

Ritchie, B. W. (2009). Crisis and disaster management for tourism. In Crisis and Disaster Management for Tourism. https://doi.org/10.21832/9781845411077

Rudiyanto, A., \& Sugiarto, E. (2020). "New Normal" Sebagai Momentum Kebangkitan Ekowisata: Sebuah Kajian Awal tentang Daya Dukung Lingkungan Pascapandemi COVID-19. Pariwisata Budaya: Jurnal Ilmiah Pariwisata Agama Dan Budaya, 5(2), 75-81.

Sekaran, U., \& Bougie, R. (2016). Research Method for Business Textbook: A Skill Building Approach. In John Wiley \& Sons Ltd.

Siri, R., \& Chantraprayoon, O. S. (2017). Local community participatory learning with a nature interpretation system: A case study in Ban Pong, Sansai district, Chiang Mai, Thailand. Kasetsart Journal of Social Sciences.

https://doi.org/10.1016/j.kjss.2016.04.003

Sudarti \& Hindiyati, S. H. (2021). Respon Masyarakat Terhadap Reklamasi Lahan Bekas Tambang Semen Sebagai Ekowisata Di Daerah Sale Kabupaten Rembang. Pariwisata Budaya: Jurnal Ilmiah Pariwisata Agama dan Budaya, 6(1), 74-79.

Suryanti, P. E \& Indrayasa, K. B. (2021). Perkembangan Ekowisata Di Bali : "Upaya Pelestarian Alam Dan Budaya Serta Pemberdayaan Masyarakat Lokal". Pariwisata Budaya: Jurnal Ilmiah Pariwisata Agama dan Budaya, 6(1), 49-56.

Tanaka, N., Sasaki, Y., Mowjood, M. I. M., Jinadasa, K. B. S. N., \& Homchuen, S. (2007). Coastal vegetation structures and their functions in tsunami protection: Experience of the recent Indian Ocean tsunami. Landscape and Ecological Engineering. https://doi.org/10.1007/s11355-006-0013-9

Tuwo, A. 2011. Pengelolaan Ekowisata Pesisir dan Laut; Pendekatan Ekologi, SosialEkonomi, Kelembagaan dan Sarana Wilayah. Brillian Internasional. Surabaya.

Vermaat, J. E., \& Thampanya, U. (2006). Mangroves mitigate tsunami damage: A further response. Estuarine, Coastal and Shelf

Science. https://doi.org/10.1016/j.ecss.2006.04.019

Wardiyanto \& Baiquni, M. (2011). Perencanaan dan Pengembangan Pariwisata. Bandung:
Lubuk Agung

Wisdom, J., \& Creswell, J. W. (2013). Integrating quantitative and qualitative data collection and analysis while studying patient-centered medical home models. Agency for Healthcare Reseach and Quality. https://doi.org/No. 13-0028-EF.

Wulung, S. R. P., \& Abdullah, C. U. (2020). Upaya Mitigasi Pasca Tsunami Di Destinasi Pariwisata. Media Bina Ilmiah.

\section{BIODATA PENULIS}

Rizkaf Zulfikar Kasim, Merupakan kandidat magister pariwisata berkelanjutan dari Magister Pariwisata Berkelanjutan, Sekolah Pascasarjana, Universitas Padjadjaran. Memiliki latar belakang keilmuan arsitektur lanskap, spesialisasi penelitiannya adalah perencanaan lanskap destinasi wisata dan perencanaan lanskap berbasis mitigasi bencana.

Dr. Ute Lies Siti Khadijah, M.Si Merupakan Doktor Ilmu Komunikasi yang saat ini menjabat sebagai Ketua Program Studi Perpustakaan dan Sains Informasi, Fakultas Ilmu Komunikasi, Universitas Padjadjaran. Spesialisasi penelitiannya terkait preservasi budaya, mitigasi bencana dan pariwisata. ID Google Scholar: Pm9uWaIAAAAJ\&hl

Dr. Cecep Ucu Rakhman, M.M Merupakan Doktor Ilmu Budaya (Pariwisata) Universitas Padjadjaran. Saat ini menjabat sebagai dosen tetap di Program Pascasarjana Sekolah Tinggi Pariwisata Bandung. Spesialisasi penelitiannya adalah terkait studi pariwisata budaya, pemberdayaan masyarakat dan pariwisata berkelanjutan. ID Google Scholar: uyDb29MAAAAJ

Rifki Rahmanda Putra, S.Par., M.Par merupakan alumni Magister Pariwisata Berkelanjutan, Sekolah Pascasarjana, Universitas Padjadjaran. Spesialisasi penelitiannya adalah terkait perencanaan dan pengembangan daya tarik atau destinasi wisata, kajian pasar wisatawan, pariwisata berkelanjutan dan pariwisata berbasis masyarakat. ID Google Scholar: nJ2GJNsAAAAJ 